\title{
GNSS RTK Application to Determine Coastline Case Study at Northen Area of Sulawesi and Gorontalo
}

\author{
Wahyudi Nugraha ${ }^{1}$, Andri Daniel Parapat ${ }^{2}$, Dewi Sekar Arum ${ }^{3}$, and Fatichatus Istighfarini ${ }^{4}$ \\ 1,2,3,4 Geospatial Information Agency, 16911 Cibinong West Java, Indonesia
}

\begin{abstract}
Article 12 of Indonesia Government Regulation No.4-year 2011 about Geospatial Information [5], coastline is an element of base map. Article 13 subsection 1 states that the boundary form between the land and the ocean were affected by the tides. In subsection 2, coastline is divided into three types, namely lowest, highest, and mean sea level tides. Studies about coastline is important to support many maritime activities such as to determine administrative area (such as province, etc.), determine the length of coastline, coastal and marine management, also inland and marine spatial planning. Due to the importance of coastline, data with good accuracy is needed. Coastline mapping technology has developed rapidly. Previous method of coastline mapping is to trace marine debris carried by wave to the coast. At present time, because of needs of coastline data with higher accuracy and in the bigger scales, the GNSS RTK technology is starting to be used. GNSS technology generated coordinates and elevation and use tides values as reference datum. After the above, Digital Elevation Model generated from those points are combined with bathymetry and land elevation data resulting three types of coastline in accordance with the Indonesia Government Regulation about Geospatial Information Article 13 Subsection 2.
\end{abstract}

\section{Introduction}

As a maritime nation, coastline determination in Indonesia is necessary to support many maritime activities such as to determine administrative area (such as province, etc.), determine the length of coastline, coastal and marine management, also inland and marine spatial planning.

Previously, coastline mapping is to trace marine debris carried by wave to the coast, using GPS handheld. As states on Indonesia Government Regulation No.4-year 2011 about Geospatial Information [5], article 12 states that coastline is one of the elements of base map. Article 13 subsection 1 states that the boundary form between the land and the ocean were affected by the tides. In subsection 2, coastline is divided into three types, namely lowest, highest, and mean sea level coastline. After the regulation has been legalized, the GNSS handheld is no longer relevant to be used because the three types of coastline cannot be generated.

Coastline determination has been described in many studies with different methods. Khomsin [6] used rectified SPOT 7 Imagery to determine coastline in high water level by interpreting the visual appearance of objects natural color composite as the firm boundaries between sea and land. in term of the advantage of using the GNSS technology, Gonclaves [3] described that GNSS-based method offers a quicker, all-weather, highly accurate and continuously updatable shoreline positional time series relevant for monitoring and management task. Mendonça [8] used kinematic GNSS for shoreline monitoring as it has advantages of being able to produce consistent data for temporal analysis. the result shows that for temporal analysis of five years, the shoreline constantly changes in different periods.

We organize the study as follows: section 2 explains about method used in the study, area, and data collection. Section 3 explains about the results from the study and analysis. The study is concluded in section 4 .

\section{Method}

Data needed in the study are:

- Tidal measurement data,

- Bathymetry data,

- Benchmark (BM) measurement data,

- Levelling measurement from BM to tide station,

- Coastline data tracking using GNSS RTK.

Flowchart of the study can be seen on Fig. 1.

* Corresponding author: wahyudi.nugraha@big.go.id 


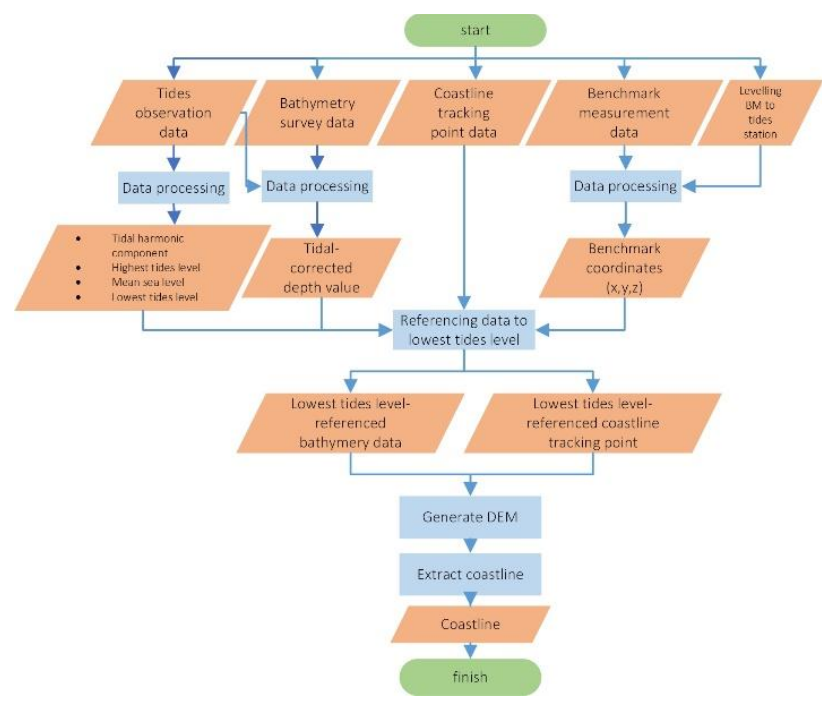

Fig. 1. Flowchart of the Study

\subsection{Study Area}

The study area for this paper is located in the Northern area of Sulawesi Island, that included to North Sulawesi and Gorontalo Province of Indonesia, see Fig. 2. Area of study is along the coastline of the study area with approximately 750 kilometres in length. Data acquisition for this study retrieved in 2017.

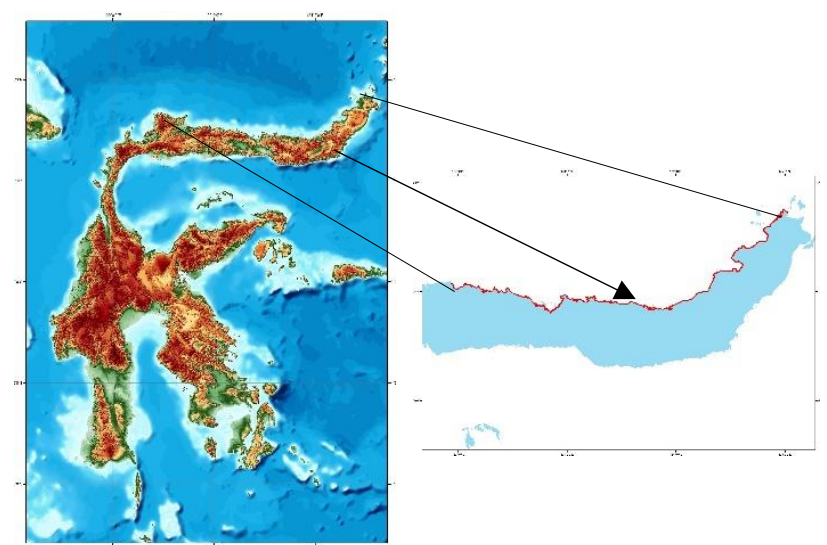

Fig. 2. Study Area (Source: NKRI Maps of Geospatial Information Agency)

\subsection{Data Collection}

Data collection for this study contains several activities. Those are tidal observation, levelling from BM to tide station, bathymetry survey, and coastline tracking. Fig.3 represented the process to determine coastline using GNSS RTK.

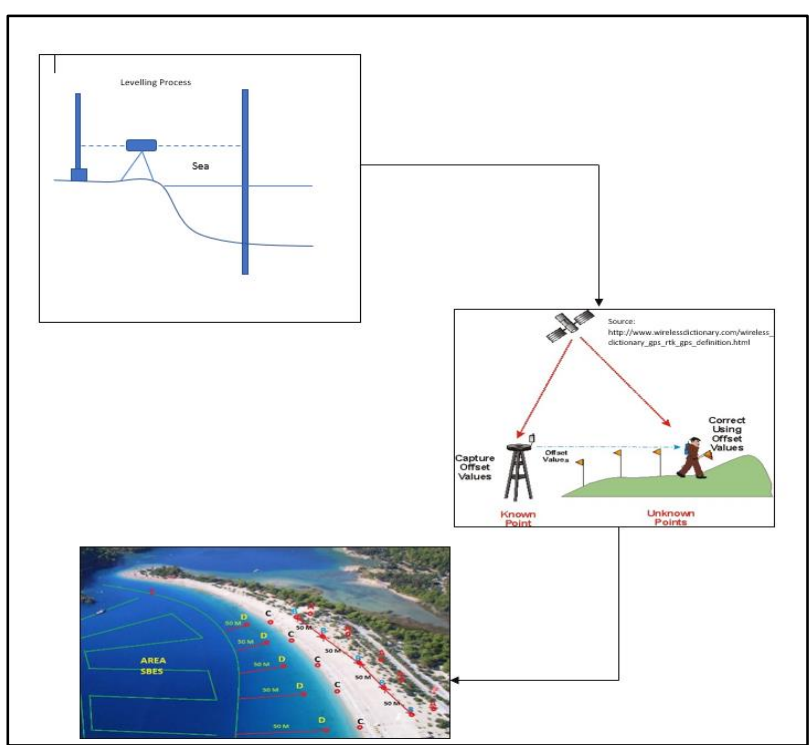

Fig. 3. Schema to determine coastline

\subsubsection{Tides and Levelling}

Tidal observation needs to be done at least 30 days of observation. This observation can be done using AWLR (Automatic Water Level Recorder) with an observation interval every 5 minutes. The observation can be assisted with manual tide observation, which has observation interval every hour. Along with this observation, levelling process needs to be done to determine the value of highest, lowest, and mean sea level according to BM. For tracking measurement using RTK, the final result of tides values is used as a reference. In the survey area, 19 tides station are built to find out the characteristics of tides. Because of the device and environmental factor, the data which can be used only from 15 tides stations. The tides station installation will be depending on the characteristics of the area, therefore there are some terms and conditions refers to the national standard of Indonesia about tides station installation (SNI 7924:2013). Those are: must not be placed in estuary, must be placed in stable position which is not affected by direct wave but still have a direct access to the sea in both conditions (high and low), can be accessed in every weather and conditions, the depth value around that area is homogeny. The area of this study is using two types of tides station, port and temporary tide building, see Fig. 4. 


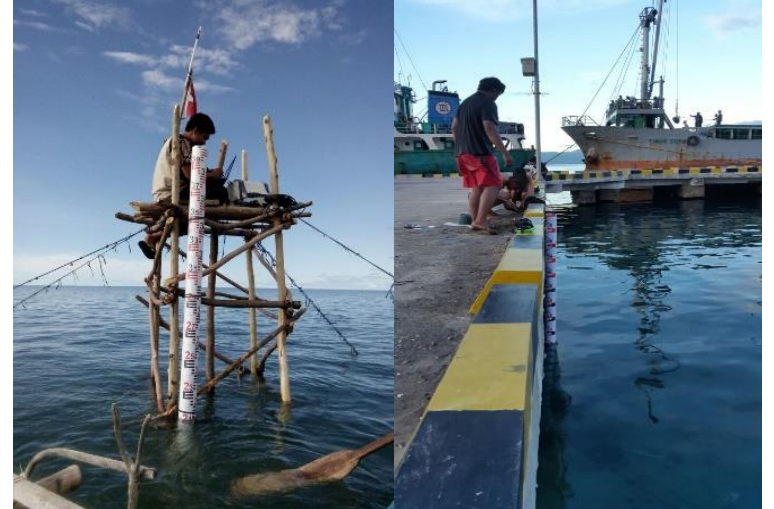

Fig. 4. Installation tide stations.

\subsubsection{Bathymetry Data}

Depth values of survey area generated from bathymetry survey using single beam echosounder. Bathymetry survey focused on shallow area, which depth is 5 metres or less. The survey was done near to the coast, as near as it can be, and also on the high tide during the survey time.

The collected depth values were later referenced to defined datum, which in this study, lowest tide is used. This data is used as a complement for tracking data inshore to intertidal zone. Bathymetry data acquisition will start after lowest tide zone. Both of the data will be combined to form elevation profile for coastal area up to shallow area. See Fig 5.

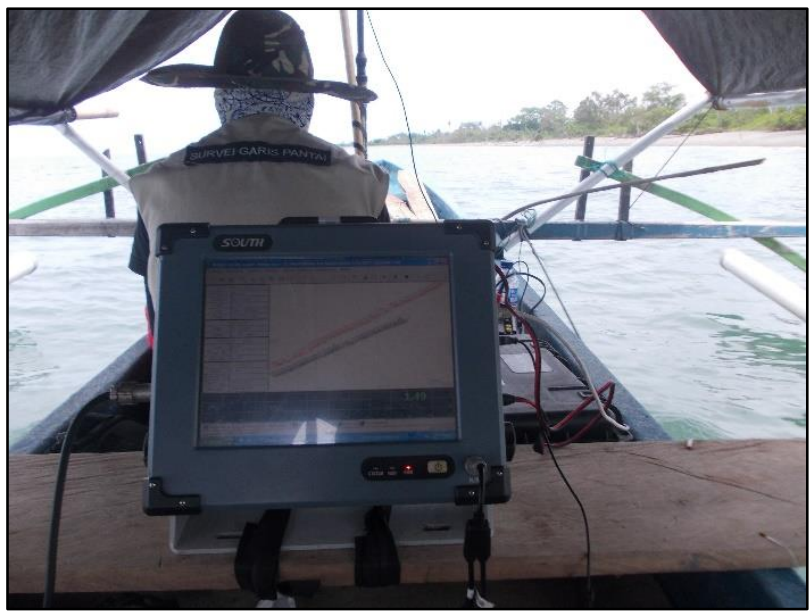

Fig. 5 Acquisition bathymetry data

\subsubsection{GNSS RTK Tracking Data}

For coastline tracking data acquisition using differential method of radio RTK. Every point must be bounded to Benchmark which already attached to tides station. Illustration of data tracking acquisition can be seen in Fig 6.

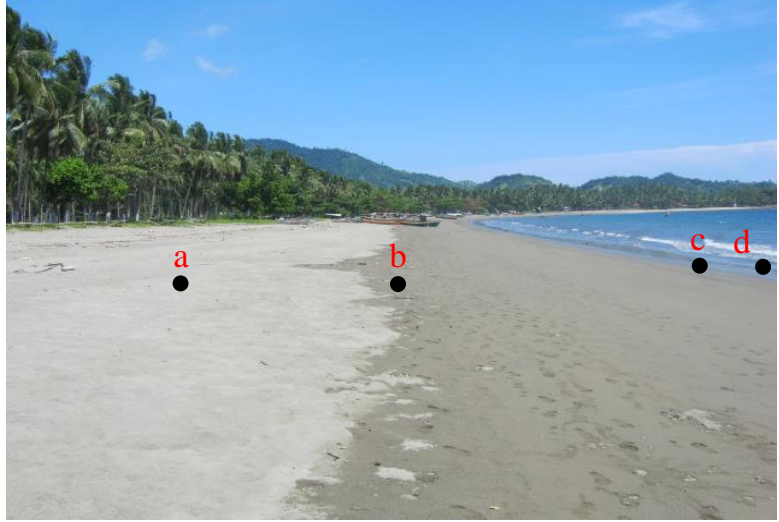

Fig. 6 Illustration RTK tracking

Figure explanation:

Point $\mathrm{a}=$ This point located in land that can be indicated it never affected by highest water level and can be noted by vegetation

Point $b=$ This point can be indicated as mean sea level. This point marked by the wet condition of sand beach and have a contrast color with sand area in land.

Point $\mathrm{c}=$ This point is intersection between land and waters sea level at that time.

Point $d=$ This point is considered to have lowest tide elevation

If in the field there are areas cannot be surveyed and reached because of natural conditions in that area, such as cliff or dense mangrove forest, secondary data like satellite imagery can be used. Tracking documentation can be seen in Fig 7. Three until four months were the time needed to measure all RTK point along North Sulawesi and Gorontalo Province.

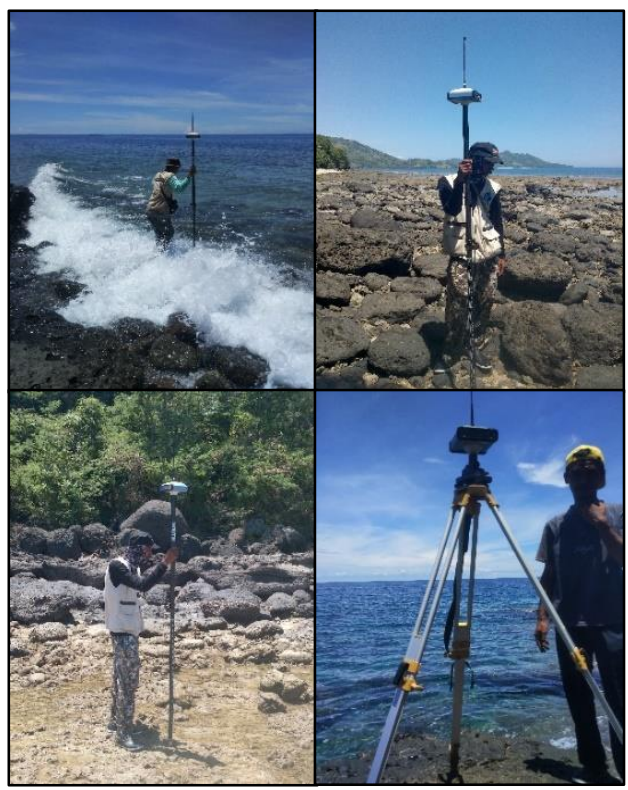

Fig. 7 Documentation tracking RTK 


\section{Results and Analysis}

\subsection{Tidal Data Processing}

Table 1 Result of tidal processing

\begin{tabular}{|c|c|c|c|c|c|c|c|c|c|c|c|c|c|c|c|}
\cline { 2 - 15 } \multicolumn{1}{c|}{} & PS_01 & PS_03 & PS_04 & PS_06 & PS_07 & PS_09 & PS_10 & PS_11 & PS_12 & PS_13 & PS_14 & PS_15 & PS_16 & PS_17 & PS_19 \\
\hline MSL & 1,60 & 1,71 & 1,58 & 1,83 & 1,91 & 2,06 & 1,71 & 2,05 & 3,09 & 2,21 & 1,77 & 1,69 & 1,68 & 1,32 & 1,61 \\
\hline Lowest & 0,43 & 0,51 & 0,43 & 0,65 & 0,72 & 0,82 & 0,43 & 0,80 & 1,86 & 0,94 & 0,49 & 0,38 & 0,42 & 0,11 & 0,43 \\
\hline Highest & 3,02 & 3,08 & 3,05 & 3,25 & 3,28 & 3,40 & 3,09 & 3,37 & 4,39 & 3,46 & 3,23 & 3,07 & 3,04 & 2,62 & 2,88 \\
\hline Z0 & 1,17 & 1,20 & 1,15 & 1,19 & 1,19 & 1,25 & 1,28 & 1,25 & 1,23 & 1,28 & 1,27 & 1,30 & 1,27 & 1,22 & 1,18 \\
\hline Range & 2,58 & 2,58 & 2,62 & 2,60 & 2,56 & 2,59 & 2,66 & 2,58 & 2,53 & 2,52 & 2,74 & 2,69 & 2,62 & 2,51 & 2,45 \\
\hline
\end{tabular}

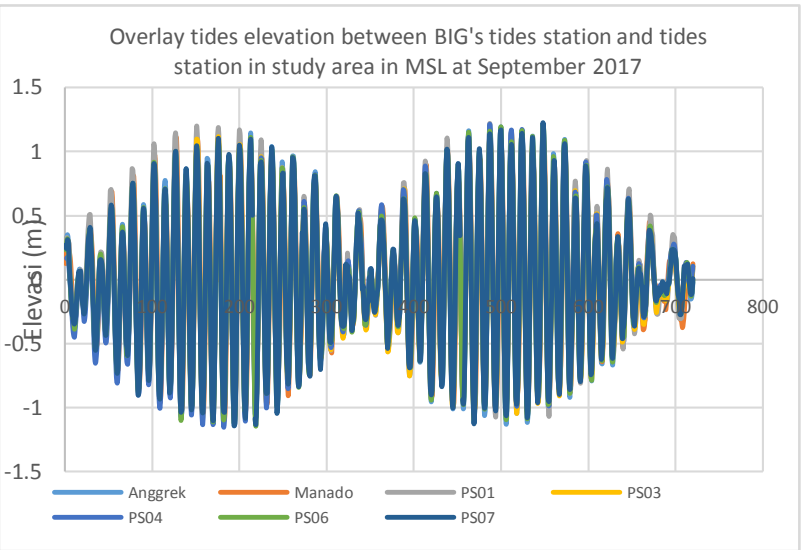

Fig. 8 Graphic comparison tide data between BIG station with several tidal processing.

Tidal data processing has a purpose to get the value of highest, lowest, and mean sea level elevation. Tidal data processed by least square method with the help of UTide MATLAB program [2]. UTide processed tidal data to produce tidal harmonic constituents. Tidal harmonic constituents are needed to generate tidal prediction data in one year after time of tides measurement. Value of highest, lowest, and mean sea level elevation are derived from this tidal prediction data. The results of tidal processing data in 15 from 19 tides station at survey area can be seen in Table.1 The value of highest, lowest, and mean sea level elevation still referenced to each local tides station, and location tides station can be seen in Fig.9.

We also processed tides data from BIG tides station in Anggrek and Manado to compare with several tidal processing data results from tides station survey area. The results can be seen in Fig.8 We chose one value of highest, lowest, and mean sea level elevation from 15 results of tidal processed data as a reference to generate coastline vector from DEM interpolation. We did this because the coastline vector elevation must be in one value and seamless line. Lowest sea level elevation from tide station was chosen as a reference elevation for all data.

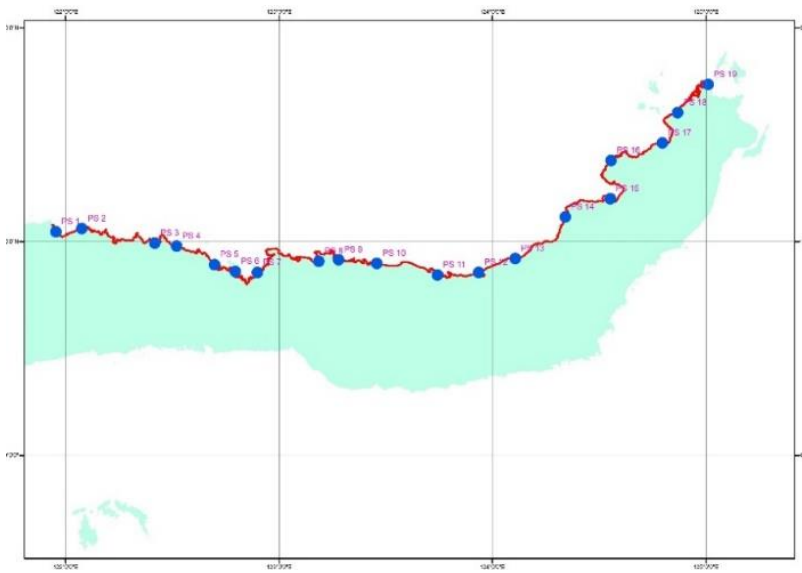

Fig. 9 Tides station location at survey area

\subsection{Bathymetry and RTK Tracking Data Processing}

First, bathymetric data that obtained from bathymetric survey using Singlebeam Echosounder needs to be cleaned from spike or outlier data. Then, cleaned data needs barcheck correction and tidal correction to get final bathymetric data with good accuracy. To make sure that the data has a good accuracy is to compare bathymetric data from main sounding survey line and cross sounding survey line. In this research, we use Orde $1 \mathrm{~b}$ IHO SP 44 standard [4] to check the data. The result is we got $95,02 \%$ confidence level that indicated the data are good. The last step is to reference bathymetric data to lowest sea level.

GNSS RTK tracking data consists of horizontal coordinates and height value that referenced to benchmark point. GNSS RTK tracking data precision level is under 1 meter in order to fulfil level of accuracy in large-scale mapping. GNSS RTK tracking data processing only reference height value of RTK tracking data to lowest sea level. The method is reference height value of benchmark point to lowest sea level using height difference from benchmark point to tidal station. 


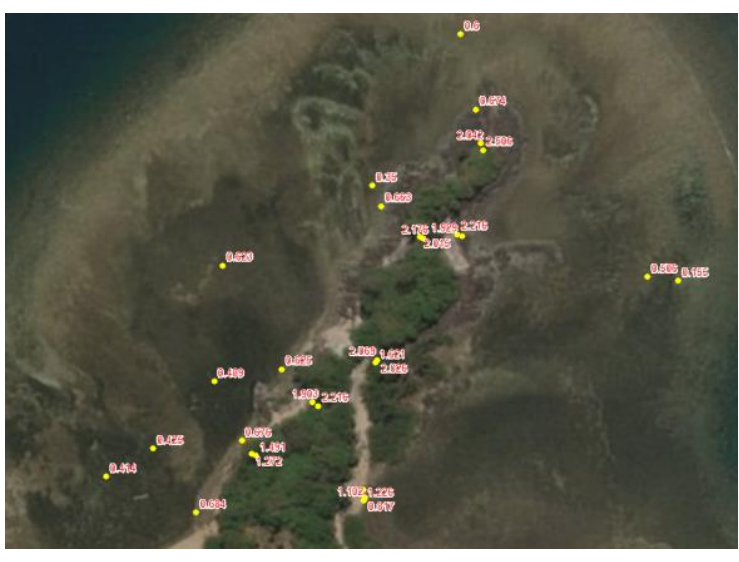

Fig. 10 Sample of referenced RTK Tracking Data

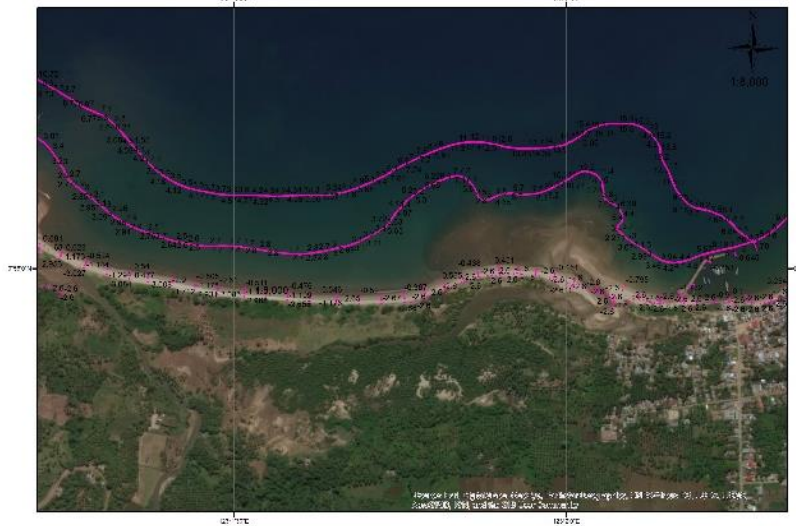

Fig. 11 Sample of referenced Bathymetric data

Table 2 Check confidence level bathymetry data

\begin{tabular}{|c|c|c|c|c|c|c|c|c|}
\hline ID_CROSS & DATE & TIME & $x$ & $Y$ & $Z$ & FORMULA & DEVIATION & ANNOTATION \\
\hline 4 & $12 / 06 / 2017$ & $15: 21: 21$ & 558399.3 & 98179.81 & 6.005556 & 0.5060586 & 0.222 & ENTER TOLERANCE \\
\hline 4 & $11 / 03 / 2017$ & $10: 38: 13$ & 558400.1 & 98180.05 & 5.783556 & $x$ & $\mathbf{x}$ & $x$ \\
\hline 5 & $12 / 06 / 2017$ & $15: 12: 11$ & 559488.7 & 98179.63 & 4.860556 & 0.5039768 & 0.142 & ENTER TOLERANCE \\
\hline 5 & $11 / 03 / 2017$ & 10:31:12 & 559487.5 & 98180.48 & 4.718556 & $x$ & $x$ & $x$ \\
\hline 9 & $12 / 06 / 2017$ & $15: 23: 56$ & 558105.3 & 98204.75 & 6.388556 & 0.5068506 & 0.222 & ENTER TOLERANCE \\
\hline 9 & $11 / 03 / 2017$ & $10: 40: 07$ & 558106.6 & 98205.41 & 6.166556 & $x$ & $\mathrm{x}$ & $x$ \\
\hline 10 & $12 / 06 / 2017$ & $15: 24: 25$ & 558043.8 & 98211.84 & 6.469556 & 0.5070242 & 0.319 & ENTER TOLERANCE \\
\hline 10 & $11 / 03 / 2017$ & 10:40:32 & 558042.6 & 98212.81 & 6.150556 & $x$ & $x$ & $x$ \\
\hline 13 & $12 / 06 / 2017$ & 15:26:55 & 557776 & 98240.48 & 6.820556 & 0.507801 & 0.357 & ENTER TOLERANCE \\
\hline 13 & $11 / 03 / 2017$ & 10:42:15 & 557776.4 & 98240.5 & 6.463556 & $x$ & $x$ & $x$ \\
\hline 19 & $12 / 06 / 2017$ & 14:58:08 & 561190.5 & 98333.47 & 5.875556 & 0.5058006 & 0.451 & ENTER TOLERANCE \\
\hline 19 & $11 / 03 / 2017$ & $10: 20: 24$ & 561190.2 & 98333.64 & 5.424556 & $x$ & $x$ & $x$ \\
\hline 22 & $12 / 06 / 2017$ & 14:53:02 & 561614 & 98366.71 & 4.024556 & 0.5027298 & 0.257 & ENTER TOLERANCE \\
\hline 22 & $11 / 03 / 2017$ & 10:17:43 & 561614.3 & 98367.11 & 3.767556 & $x$ & $x$ & $x$ \\
\hline 24 & $12 / 06 / 2017$ & $15: 37: 14$ & 556389.5 & 98375.09 & 6.395556 & 0.5068655 & 0.335 & ENTER TOLERANCE \\
\hline 24 & $11 / 03 / 2017$ & 10:51:07 & 556391.2 & 98377.44 & 6.060556 & $x$ & $x$ & $x$ \\
\hline 25 & $11 / 03 / 2017$ & $10: 16: 29$ & 561812 & 98390.38 & 3.612556 & 0.5022007 & -0.128 & ENTER TOLERANCE \\
\hline 25 & $12 / 06 / 2017$ & $14: 51: 27$ & 561813.7 & 98391.26 & 3.740556 & $x$ & $x$ & $x$ \\
\hline 27 & $11 / 03 / 2017$ & $10: 15: 48$ & 561922.5 & 98408.3 & 3.437556 & 0.5019931 & -0.34 & ENTER TOLERANCE \\
\hline 27 & $12 / 06 / 2017$ & $14: 50: 39$ & 561922.9 & 98409.17 & 3.777556 & $x$ & $x$ & $x$ \\
\hline 28 & $12 / 06 / 2017$ & $15: 39: 27$ & 556100.1 & 98414.99 & 5.193556 & 0.5045378 & 0.359 & ENTER TOLERANCE \\
\hline 28 & $11 / 03 / 2017$ & 10:53:00 & 556100 & 98418.21 & 4.834556 & $x$ & $x$ & $x$ \\
\hline 32 & $30 / 10 / 2017$ & 10:52:05 & 555656.4 & 98446.46 & 1.122556 & 0.5002129 & -0.269 & ENTER TOLERANCE \\
\hline 32 & $12 / 06 / 2017$ & $15: 42: 22$ & 555657.7 & 98446.75 & 1.391556 & $x$ & $x$ & $x$ \\
\hline 33 & $11 / 03 / 2017$ & $10: 14: 33$ & 562121.9 & 98448.69 & 3.059556 & 0.5015795 & -0.261 & ENTER TOLERANCE \\
\hline 33 & $12 / 06 / 2017$ & $14: 48: 54$ & 562121.1 & 98449.51 & 3.320556 & $x$ & $x$ & $x$ \\
\hline 34 & $12 / 06 / 2017$ & $14: 48: 30$ & 562183 & 98461.32 & 3.113556 & 0.5016356 & 0.216 & ENTER TOLERANCE \\
\hline 34 & $11 / 03 / 2017$ & 10:14:10 & 562182.6 & 98461.61 & 2.897556 & $x$ & $x$ & $x$ \\
\hline 36 & $12 / 06 / 2017$ & $15: 45: 48$ & 555169.3 & 98504.95 & 2.159556 & 0.5007875 & 0.1875 & ENTER TOLERANCE \\
\hline 36 & $30 / 10 / 2017$ & $10: 47: 37$ & 555170.2 & 98505.17 & 1.972056 & $x$ & $\mathbf{x}$ & $x$ \\
\hline 37 & $30 / 10 / 2017$ & $10: 46: 54$ & 555090 & 98507.59 & 1.853056 & 0.50058 & -0.0475 & ENTER TOLERANCE \\
\hline 37 & $12 / 06 / 2017$ & $15: 46: 23$ & 555089.4 & 98507.9 & 1.900556 & $x$ & $x$ & $x$ \\
\hline 38 & $30 / 10 / 2017$ & 10:50:05 & 555440.8 & 98509.4 & 1.216056 & 0.5002499 & -0.1955 & ENTER TOLERANCE \\
\hline 38 & $12 / 06 / 2017$ & 15:43:52 & 555440.5 & 98510.18 & 1.411556 & $x$ & $x$ & $x$ \\
\hline 39 & $12 / 06 / 2017$ & 15:44:27 & 555356.4 & 98510.56 & 1.650556 & 0.5004602 & 0.1465 & ENTER TOLERANCE \\
\hline 39 & $30 / 10 / 2017$ & $10: 49: 20$ & 555357 & 98512.07 & 1.504056 & $x$ & $x$ & $x$ \\
\hline 40 & $30 / 10 / 2017$ & $10: 44: 03$ & 554762.2 & 98510.27 & 1.305056 & 0.5002878 & -0.5195 & ENTER TOLERANCE \\
\hline 40 & $12 / 06 / 2017$ & $15: 48: 40$ & 554762.9 & 98510.47 & 1.824556 & $\mathrm{x}$ & $\mathrm{X}$ & $x$ \\
\hline
\end{tabular}




\subsection{Generating DEM and Coastline}

Bathymetric data and RTK tracking data point that referenced to lowest sea level are used to generating DEM that used to extract coastline data. In this paper, we use Natural Neighbor method in ArcGIS to create the DEM after considered distribution of the data that spread not evenly and with the least consume time to create. The Natural Neighbors interpolation method was introduced by Sibson [9]. The model works by finding the nearest subset of samples for a given cell without a measured value, and then applies weights to the samples based on the proportional area they occupy [9]. This method is well known for its ability to interpolate scattered and unevenly distributed data $[7,10]$. The result can be seen in Fig. 12

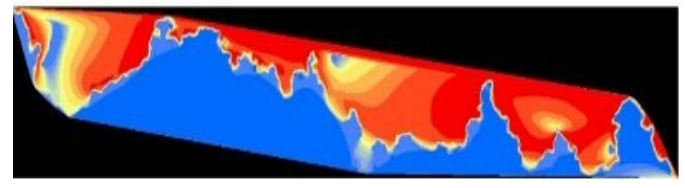

Fig. 12 DEM interpolation result
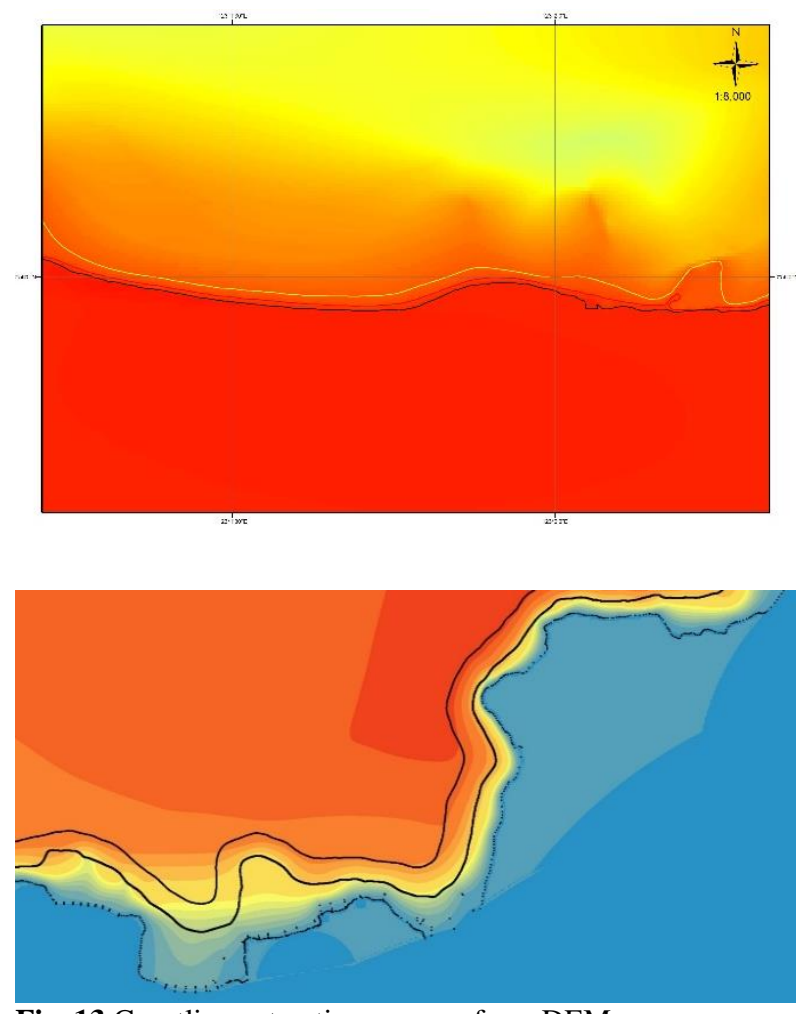

Fig. 13 Coastline extraction process from DEM

We extract coastline data from DEM with the value of highest, lowest, and mean sea level that we choose from tidal processing data that referenced to lowest sea level value. The result can be seen in Fig.13

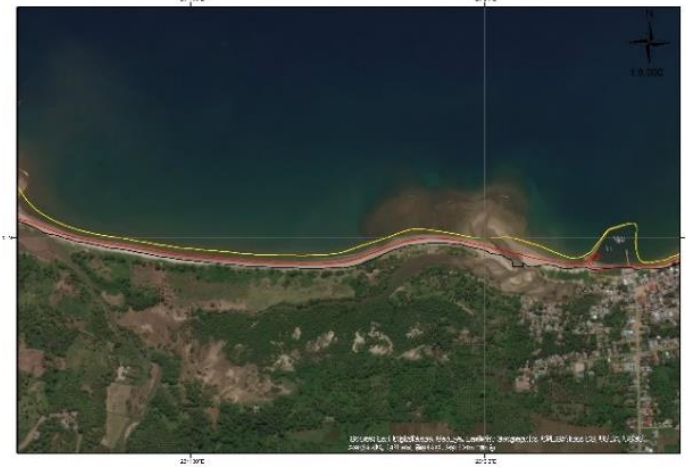

Fig. 14 Final result 3 coastline

\section{Conclusions}

GNSS Real Time Kinematic (RTK) method can be used as a method to determine highest, lowest, and mean sea level coastline. In order to extract three coastline vector data needs DEM that created from RTK tracking point and bathymetric data that referenced to lowest sea level. We use Natural Neighbor method to creates DEM then to extract coastline data. This method create DEM with less time than Kriging method. But, in the next research, we will try to use Kriging method to create DEM and compared the result with Natural Neighbor method.

Advantage of this method is accuracy level of coastline data that can be used in large-scale mapping especially in $1: 10.000$. This is because the coastline data that generated from DEM that formed from RTK tracking data and bathymetric data were good and met the required criteria for large-scale mapping. To make sure, validation of coastline data still needed in the future. Another advantage is if the area measured not to large has a low budget operation compared to another method such as LiDAR or photogrammetry.

Disadvantage of this method is the time taken to complete the measurement of RTK tracking data will be long. In this paper, RTK tracking measurement needed three until four months to completed. Another shortcoming is we can measure RTK tracking data only in the sandy coast area. Coast which has cliff or mangrove characteristic cannot be measured. In this area, we need referenced topographic data that obtained from LiDAR or photogrammetry method.

However, GNSS RTK method to determine coastline is still applicable in most area in Indonesia and with the need of large-scale mapping of coastline data.

\section{References}

1. H. Z. Abidin, GPS Positioning and Application. Jakarta: Pradnya Paramita (2007)

2. D.L. Codiga, Unified Tidal Analysis and Prediction Using the UTide Matlab Functions. Technical Report 2011-01. Graduate School of Oceanography,

\footnotetext{
Corresponding author: wahyudi.nugraha@big.go.id
} 
University of Rhode Island, Narragansett, RI. 59pp (2011)

3. Goncalves, Awange and Krueger. GNSS-based monitoring and mapping of shoreline position in support of planning and management of Matinhos/PR (Brazil) (2012)

4. International Hydrographic Organization, IHO Standard for Hydrographic Surveys $5^{\text {th }}$ Edition, February 2008 - Special Publication No. 44. Monaco: International Hydrographic Bureau (2008)

5. Indonesia Government Regulation No.4-year 2011 about Geospatial Information.

6. Khomsin and S Intan Ary Prayogi, IOP Conf. Ser.: Earth Environ. Sci. 135012019 (2018)

7. Ledoux, H.; Gold, C. An Efficient Natural Neighbour Interpolation Algorithm for Geoscientific Modelling; Springer: Berlin/Heidelberg, Germany; pp. 97-108 (2005)

8. Mendonça, F. J. B. et al. Temporal Shoreline Series Analysis Using GNSS. BCG - Boletim de Ciências Geodésicas - On-Line version, p. 701-719 (2014)

9. Sibson, R. A brief description of natural neighbor interpolation. In Interpreting Multivariate Data; John Wiley \& Sons: Hoboken, NJ, USA; pp. 21-36 (1981)

10. S. Salekin; J.H. Burgess; J. Morgenroth; E.G. Mason; D.F. Mason. ISPRS International Journal of GeoInformation. A Comparative Study of Three NonGeostatistical Methods for Optimising Digital Elevation Model Interpolation. 7, 300. (2018) 